\title{
The Effects of Adding Motivational Elements to User Instructions
}

\author{
Nicole Loorbach \\ University of Twente \\ n.r.loorbach@utwente.nl
}

\author{
Joyce Karreman \\ University of Twente \\ j.karreman@utwente.nl
}

\author{
Michaël Steehouder \\ University of Twente \\ m.f.steehouder@utwente.nl
}

\begin{abstract}
This paper gives an overview of three studies that we conducted to investigate the effects of motivational elements in user instructions. We tested for effects on usability, in particular on task effectiveness, task efficiency and user satisfaction. Motivational elements are textual additions or modifications to user instructions with the aim of motivating the reader, without changing the content of the actual instructions. The results of our studies showed that supplying motivation in user instructions can positively affect usability, but the presence of these effects seems to depend on the task at hand and on the characteristics of the user group. Our upcoming studies will focus on reading-to-do situations and on users with low confidence levels.
\end{abstract}

satisfaction measures the extent to which users are free from discomfort, and their attitudes towards the use of the product" $[1$, p.10]. Such measures are subjective in nature and harder to assess than the first two aspects of usability. This may be an explanation for the fact that so far, most research in technical communication has primarily focused on effectiveness and efficiency aspects of documents, and not on the user satisfaction aspect. Also, more and more pleas can be heard to incorporate this third aspect in the design phase of technical documents. Although the terminology that is used varies from engaging readers [2] to motivating [3] and even seducing them [4], all pleas boil down to going beyond merely enabling effective and efficient task performance with the help of the instruction manual.

Horton clearly explains the difference between documents that focus on effectiveness and efficiency of task performance - in his words "friendly documents" [4, p.6] - and documents that focus on user satisfaction as well - in Horton's words "seductive documents" [4 n 61

\section{Introduction}

\footnotetext{
Standard 92

Standardizatio] which a produr specified goal: satisfaction in extent to whis manual) is us: aspects: 1) e satisfaction. performance. , equals the "ac achieve specifi the "resources completeness I such, both eff harsh measure either perforı completely or accurately con measured in : usability, how during the use emotions. AC

\section{Assigning speed dial - (menu 2 10)}

If you have assigned a phone number to a speed dial key and you have turned on the feature Speed dial, then it is possible to dial this phone number turned on the feature Speed dial, then it is possible to dial this phone num
quickly by holding the assigned speed dial key for one second when the phone is in standby mode. A speed dial key can be assigned to either a call (the corresponding phone number will be dialed) or an SMS (a text message can be typed in, which will be sent to the corresponding phone number).

Warning If fewer than eleven phone numbers have been saved in the phone book, then these phone numbers are automatically shown next to the available speed dial keys. However, these have not yet been assigned to this key.

Warning A phone number can only be assigned to a speed dial key when it is saved in the phone book, so it is not possible to assign a phone number to a speed dial key straight away.

Mrs. Damhuis is enjoying her daily walks with Ranka, her faithful dog, to the fullest. Her rheumatoid arthritis is causing her to not always walk as far as she would like to, but on good days, she likes walking an extra bit to visit her daughter and grandson. To make sure she walks that far for good reason, she uses her Nokia 1100 to ask if they are up for her visit. Because she assigned their phone number to speed dial key 2 , all she has to do is press the 2 a little longer and the phone takes care of the rest. So typing in a phone number or using the phone book is no longer necessary!

Assigning speed dial key

1. Press -7 Menu and select Contacts

2. Select Speed dial.

Key 2: is shown in the display, accompanied by the name and phone number that are currently assigned to this key.

3. Use $\square$ or $\square$ to go to the wanted key (key 2 through key 9)

4. Press $\square$ Assign.

5. Indicate whether you wish to assign the key to a call (Assign to call) or to a text message (Assign to SMS).

6. Use $\square$ or $\square \square$ to go to the wanted name.

7. Press $\square$ Select.

$>$ Speed dial assigned to key [number of the selected key] is shown in the display.
}

Editing speed dial key

1. Press $\square$ Menu and select Contacts.

2. Select Speed dial.

Key 2: is shown in the display, accompanied by the name and phone number that are currently assigned to this key

3. Use $[\square$ or $\rightarrow$ to go to the wanted key (key 2 through key 9).

- Press - Options. You have four options: Show number

This option shows you the assigned phone number once again: 1. Press $\rightarrow$ Select

The phone number is shown in the display.

2. Press $\square$ Back to return.

- Change to call

If the speed dial key is currently assigned to a text message, then this option lets you assign it to a call:

1. Press $\square$ Select

1. Press Speed dial assigned to key [number selected key] is shown in the display.

- Change to SMS

If the speed dial key is currently assigned to a call, then this option lets you assign it to a text message:

1. Press $\rightarrow$ Select.

1. Press ras sect. Text mess. assigned to key [number selected key] is shown in the display

Remove

This option lets you assign another phone number to the speed dial key:

1. Press $\rightarrow$ Select

$>$ Remove speed dial key [number selected key]? is shown in the display.

2. Press $\square \mathbf{O K}$

$>$ Speed dial removed from key [number selected key] is shown in the display.

Warning If you wish to edit the phone number that is assigned to a speed dial key, then you should first remove the assigned phone number. This means that you should detach the phone number from the speed dial key Subsequently, you will be able to reassign the edited phone number from your phone book. 
The first step in testing the effects of supplying motivation in user instructions is finding strategies to supply motivation. An important condition in our studies was that the motivational instructions should contain the same information as the control instructions, to avoid testing for differences in content. Therefore, we tried to separate the motivational parts as much as possible from the actual instructions, resulting in so-called motivational elements. Motivational elements are textual additions or modifications to user instructions with the aim of motivating the reader, without changing the content of the actual instructions.

Our first study was exploratory in nature: we wanted to find out if motivational elements affected usability in the first place. As such, we tested the collective effects of several motivational elements. We applied six strategies to design these elements for a telephone instruction manual (see [5] for an elaborate description of these strategies):

1) Motivating users directly

For example, by providing advanced organizers.

2) Providing testimonials

That is, endorsers enthusiastically report their experiences with functions of the telephone to persuade customers to use them as well.

3) Providing anecdotes, examples and metaphors

4) Focusing on application

For example, by using the term phone book instead of number memory.

5) Emplotting the reader (cf. [3])

That is, allowing the reader "to function as a hero in a narrative of progress and improvement" (p.99).

6) Tutoring the reader

That is, adding soothing sentences and metacomments.

For our second and third study, we used Keller's ARCS Model of Motivational Design (ARCS Model) [6 7]. The ARCS model was deliberated to design motivational instructions in a reading-to-learn setting. According to the ARCS Model, four general requirements have to be met for people to be motivated to learn: (A)ttention, (R)elevance, (C)onfidence and (S)atisfaction. Practical strategies described in the model can be used to achieve each of these requirements. To design our motivational elements, we used strategies described in the ARCS Model [6 - 9] and by researchers who have applied ARCS-strategies in their own research [10 - 12].

According to the ARCS Model, the reader's attention has to be aroused and maintained throughout the instruction. To increase attention, we used the following strategies (see [13] for an elaborate description of these strategies):

1) Using color to make certain parts of the text stand out
For example, by using colored headings.

2) Offering elements that are novel or incongruous

For example, by using non-standard headings, such as questions or headings that are accompanied by sayings.

To meet the relevance requirement of the ARCS Model, the reader has to believe that the instruction is related to personal needs or goals. To increase relevance, we used the following strategies (see [14] for an elaborate description of these strategies):

1) Presenting the objectives and usefulness of the instructions

For example by adding so-called "What's coming up" sections to the beginning of each (sub)chapter of the instruction manual, which focus on several aspects of relevance by using words like useful, important, and handy.

2) Replacing technical terms with daily terms For example by using phone book and name instead of number memory and contact.

3) Providing examples that show how the product can be used

That is, adding anecdotes, scenarios and testimonials

As a third requirement, the reader needs to have confidence in his ability to learn or perform a task. To increase confidence, we used the following strategies (see [14] for an elaborate description of these strategies):

1) Presenting instructional objectives

For example by adding "What's coming up" sections as described as a relevance-increasing strategy, but these now focus on several aspects of confidence by using words like easy, without effort, and successful.

2) Inserting passages that make readers feel as part of a group in which all were once beginners

3) Letting readers know that it is okay to freely select subtopics (only when this is true)

4) Adding control steps to procedures

That is, to decrease possible feelings of uncertainty.

Finally, the student must have a sense of satisfaction with the process or results of the learning experience, to have a continuing desire to learn. Incorporating satisfaction-increasing strategies - like giving feedback during the instructions - seems virtually impossible when it comes to user instructions on paper, so we chose to offer motivational elements focusing on only the first three requirements of the ARCS Model, and to test their individual effects.

\section{Study 1: Paper-based instructions used by students in a reading-to-do setting}


In our first study (see [5] for an elaborate description), we compared two versions of an instruction manual for a fixed, wireless telephone: one improved version of the original manual (the control version) and one version that resulted from adding motivational elements to the control version (the motivational version).

The voluntary participants in this study were 40 students at the University of Twente, aged between 17 and 26. They were asked to perform 12 tasks with the telephone. Their performance on these tasks would allow us to measure both effectiveness and efficiency. To measure satisfaction, we asked the participants to answer a questionnaire both before and after they performed the tasks, about their satisfaction with the telephone and with the version of the instruction manual that they were about to use (before the tasks) or had already used (afterwards).

The results showed that motivational elements had no effect on participants' effectiveness and efficiency in using the telephone. Also, no statistically significant differences existed concerning participants' satisfaction with the telephone. However, motivational elements did increase participants' satisfaction with the instruction manual. Before task performance, participants using the motivational version rated their manual as being better and simpler than participants using the control version rated theirs. This indication was based on a six-minutescan of the manual. After task performance, the motivational version was rated as more long-winded and more written towards users than the control version. Also, both before and after task performance, participants using the motivational version rated their text as significantly more popularly written, more personal, friendlier and more fascinating than participants using the control version.

In this study, we were primarily interested in whether motivational elements would collectively bring forth the expected positive effects on the three usability aspects effectiveness, efficiency, and satisfaction. They did not concerning the first two aspects. However, possible differences in effectiveness may not have appeared due to a ceiling effect: Participants performed very well on the tasks, regardless of the manual version they used to accomplish them. The chances of encountering a ceiling effect will probably be smaller when the tasks are more difficult or when participants are less experienced with technical devices like the telephone in our study.

The motivational elements in this study positively affected one of the usability aspects, namely user satisfaction with the instruction manual. Even if the actual use of the product and the instruction manual causes users to no longer perceive the motivational version as being better and simpler than the control version, our study shows that the motivational version was still rated as more popularly written, more personal, friendlier and more fascinating than the instruction manual without motivational elements. Such qualities are exactly those aspects of attractiveness that [2] and [4] recommended writers to pay attention to in creating instructional documents. In that light, motivational elements' positive effects on users' satisfaction with the instructions may in turn motivate users to keep on trying when the going gets tough.

\section{Study 2: Paper-based instructions used by seniors in a reading-to-do setting}

In our next study (see [13] for an elaborate description), we decided to again test for the effects of motivational elements on usability, specifically on effectiveness, efficiency and user satisfaction. As a result of our first study, we also decided to test for effects of motivational elements on user motivation, for we concluded that such elements may cause users to give up trying less easily. Also, participants were no longer students, in an attempt to avoid ceiling effects when it comes to users' effectiveness and efficiency in performing tasks. Instead, we decided to ask seniors; a user group that is known for being less experienced with relatively new technology devices like cellular telephones [15].

We designed four versions of user instructions for a cellular telephone:

1) A control version, without motivational elements.

2) An A version, with motivational elements that focus on gaining and maintaining users' attention.

3) An $R$ version, with motivational elements that focus on increasing the users' sense of relevance.

4) $\mathrm{A} \mathrm{C}$ version, with motivational elements that focus on increasing users' confidence.

The participants in this study were 79 seniors, who were between 60 and 70 years of age. They performed three tasks with a cellular telephone. Contrary to the results of the first study, the results of this study did not show an effect of motivational elements on participants' satisfaction with the telephone or with the instructions. However, the results of this study did show positive effects of motivational elements that focus on relevance and confidence. These elements positively affected participants' effectiveness of task performance. Confidence elements also positively affected participants' persistence in trying to complete tasks.

\section{Study 3: Online instructions used by students in a reading-to-learn setting}


In our third study, we tested the effects of motivational elements in online instructions. We designed three Web sites ${ }^{1}$ which described the activities that students have to undertake when they are planning to study at the University of Twente in the Netherlands for some time:

1) A control version, without motivational elements.

2) An $R$ version, with motivational elements that focus on increasing the users' sense of relevance.

3) A C version, with motivational elements that focus on increasing users' confidence.

347 students of the University of Washington participated in this study. They entered the study by going to the URL of our study at a place and time of their convenience. They browsed one of the versions of the Web site. Participants answered general questions as well as questions about the comprehensibility of the text and the satisfaction with the Web site. The results of this study did not show any effects of motivational elements.

\section{Summary of the three studies}

The results of the studies showed that supplying motivation in user instructions can positively affect task effectiveness, task efficiency and user satisfaction with the instructions, but the presence of these effects seems to depend on the characteristics of the user group and on the task at hand.

Motivational elements had no effect on the task performance of the students, who participated in the first and the third study, but the elements did have positive effects on the task performance of the seniors who participated in our second study. Before they started reading the instruction manual, many seniors said that they did not expect themselves to be able to work with the telephone. The seniors' lack of self-confidence concerning electronic devices is also known from the literature [15]. Therefore, we assume that people who have a low self-confidence level benefit more from motivational elements than people who have a higher level of self-confidence.

The students who browsed the Web site (third study) did not appreciate the motivational text more than the control text, but the students who had to work with the telephone (first study) did appreciate the motivational manual more than the control manual. So, motivational elements seem to enhance user satisfaction in reading-todo situations but not in reading-to-learn situations.

Our upcoming studies will focus on reading-to-do situations and on users with low confidence levels. We

\footnotetext{
${ }^{1}$ This study was part of a larger study in which we used six Web sites to also investigate the effects of some other variables. This paper focuses on motivational elements.
}

will especially explore the effects of motivational elements that focus on increasing users' confidence.

\section{References}

[1] International Organization for Standardization. International Standard ISO 9241-11: Ergonomic requirements for office work with visual display terminals (VDTs) - Part 11: Guidance on usability, ISO, Geneva Switzerland, 1998.

[2] MacDonald, M.P. Can a manual entertain? Intercom: The Magazine of the Society for Technical Communication. 14-17, 2001.

[3] Goodwin, D. Emplotting the reader: Motivation and technical documentation. Journal of Technical Writing and Communication, 21, 99-115, 1991.

[4] Horton, W. Secrets of user-seductive documents: Wooing and winning the reluctant reader. Society for Technical Communication, Arlington VA, 1997.

[5] Loorbach, N., M. Steehouder, and E. Taal. The Effects of Motivational Elements in User Instructions. Journal of Business and Technical Communication, 20(2): 177-199, 2006

[6] Keller, J.M. Motivational Design of Instruction. In C.M. Reigeluth (Ed.), Instructional-design theories and models: An overview of their current status, 386-434, Lawrence Erlbaum Associates, Hillsdale NJ, 1983.

[7] Keller, J.M. Strategies for Stimulating the Motivation To Learn. Performance \& Instruction. 26(8): 1-7, 1987.

[8] Keller, J.M. (1990). Motivational Tactics Checklist. Unpublished materials, Florida State University.

[9] Keller, J. M., \& Kopp, T. W. (1987). An application of the arcs model of motivational design. In C. M. Reigeluth (Ed.), Instructional theories in action. Lessons illustrating selected theories and models (pp. 289-320). Hillsdale (NJ): Lawrence Erlbaum Associates.

[10] Astleitner, H., \& Hufnagl, M. (2003). The effects of situation-outcome-expectancies and of arcs-strategies on self-regulated learning with web-lectures. Joumal of educational multimedia and hypermedia, 12(4), 361-376.

[11] Chang, M., \& Lehman, J. D. (2002). Learning foreign language through an interactive multimedia program: An experimental study on the effects of the relevance component of the arcs model. CALICO Joumal, 20(1), 81-98. 
[12] Small, R. (2000). Motivation in instructional design. Teacher Librarian, 27(5), 29-31.

[13] Loorbach, N., J. Karreman, and M. Steehouder. Adding Motivational Elements to an Instruction Manual for Seniors: Effects on Usability and Motivation. Technical Communication, in press.

[14] Loorbach, N.R., J. Karreman, and M.F. Steehouder. Motivational Elements in User Instructions: Strategies to Boost the Effectiveness of Task Performance. Proceedings of the Annual Conference of the Society for Technical Communication, Las Vegas NV, 53: 261-265, 2006.

[15] Schwender, C., and C. Köhler. Introducing Seniors to New Media Technology: New Ways of Thinking for a New Target Group. Technical Communication, 53(4): 464-470, 2006.

\section{About the Authors}

Nicole Loorbach is a $\mathrm{PhD}$ candidate in the Technical and Professional Communication Department at the University of Twente, the Netherlands. Her research interests include document design and technical communication, in particular motivational elements in technical documents.

Joyce Karreman is an assistant professor in the Technical and Professional Communication Department at the University of Twente. Her research interests include user support and document design, in particular the use of different information types in instructive texts.

Michaël Steehouder is the chair of the Technical and Professional Communication Department at the University of Twente. His research interests include document design and rhetoric. $\mathrm{He}$ has published textbooks and articles about communication skills, government forms, software manuals, and user instructions. He is past president of STIC, the Dutch society for technical communication, and associate editor of IEEE Transactions on Professional Communication. 